\title{
Dynamic changes in $T A P 1$ expression levels in newborn to weaning piglets, and its association with Escherichia coli F18 resistance
}

\author{
J. Wang ${ }^{1}$, Y. Liu ${ }^{1}$, W.H. Dong ${ }^{1}$, Y.J. Huo ${ }^{1}$, X.G. Huang ${ }^{2}$, S.L. Wu ${ }^{1}$ and W.B. Bao ${ }^{1}$ \\ ${ }^{1}$ College of Animal Science and Technology, \\ Key Laboratory for Animal Genetics, Breeding, \\ Reproduction and Molecular Design of Jiangsu Province, \\ Yangzhou University, Yangzhou, China \\ ${ }^{2}$ Sutai Pig Breeding Center of Jiangsu Province, Suzhou, China \\ Corresponding author: W.B. Bao \\ E-mail: wenbinbao74@yahoo.com
}

Genet. Mol. Res. 13 (2): 3686-3692 (2014)

Received July 24, 2013

Accepted December 13, 2013

Published May 9, 2014

DOI http://dx.doi.org/10.4238/2014.May.9.12

\begin{abstract}
The transporter associated with antigen processing (TAP) transports peptides from the cytosol into the endoplasmic reticulum for subsequent loading onto the major histocompatibility complex (MHC) class I molecules. This study showed the dynamic changes in the TAPI expression level in newborn to weaning piglets. Tissue expression profiles revealed that the TAP1 gene was expressed at low levels in all tissues, and the expression levels were relatively higher in the lung, spleen, lymph, and thymus; further, no significant difference was observed in the expression in each tissue among the 3 unweaned stages $(8,18$, and 30 days). Nevertheless, the postweaning ( 35 days) expression levels in tissues, including the spleen, lung, lymph, duodenum, and jejunum were significantly higher than those in the unweaned stages. Furthermore, gene ontology and pathway analysis showed that TAP1 took part in 38 biological functions and 5 pathway processes, including $\mathrm{ABC}$ transporters and antigen processing and presentation. These analyses showed that the TAP1 gene, which was
\end{abstract}


related to MHC I immune regulation, had a stable and low expression level in unweaned stages; however, its expression increased in the postweaning stages. The high expression level of TAPl indicated that the gene might play an important role in Escherichia coli F18 resistance.

Key words: TAP1 gene; Pig; Escherichia coli F18; Real-time polymerase chain reaction

\section{INTRODUCTION}

Transporter associated with antigen processing (TAP) is a heterodimer composed of TAP1 and TAP2 subunits, and both of them have an N-terminal membrane-spanning domain and a C-terminal nucleotide-binding domain. The major function of TAP is endogenous antigen presentation (Pamer and Cresswell, 1998). Related to the immune system, TAP carries antigenic peptides, which are degraded by proteosomes from the cytosol into the endoplasmic reticulum lumen for subsequent loading onto major histocompatibility complex class I (MHC I) molecules. Then, TAP transports the peptides to the cell surface to induce the specific recognition of $\mathrm{CD}^{+} \mathrm{T}$ cells (Cresswell et al., 1999). Therefore, TAP is related to autoimmune disease.

Recently, the study of diarrhea and edema has made some improvements. Escherichia coli F18 is one of the primary causative agents of these diseases. Specifically, with fimbriae, $E$. coli F18 can adhere to the receptor of enterocytes. Then, the bacterium settles, reproduces and produces enterotoxin, which can cause disease in piglets (Bertin and Duchet-Suchaux, 1991). Vögeli et al. (1997) found that the alpha-1,2-fucosyltransferase (FUT1) gene mutation, which is a G/A mutation at M307, could be an effective gene marker for $E$. coli F18-resistance. However, there is no polymorphism in Chinese local breeds, demonstrating that there are some genetic differences in E. coli F18-resistance between local breeds and foreign breeds (Bao et al., 2008). Based on the paired full-sib individuals that were selected from an established resource of Sutai pigs (Duroc x Meishan) that were characterized as resistant or sensitive to E. coli F18, our research team identified the expression profiles of some genes, including TAP1, in duodenum. The results showed that TAP1 played a vital role in resisting E. coli F18 infection (Bao et al., 2012).

At present, some researchers have reported that TAPI could be an effective anti-E. coli F18 molecular marker in pig, and it also correlated with virus infection (Ambagala et al., 2000, 2003; Chen and Wu, 2009). Sun et al. (2012) used real-time polymerase chain reaction (PCR) and found that TAP1 had high expression levels in immune tissues. TAP1 plays a significant role in immune responses because of its increased expression level after infection by virus and bacterium. Hence, this article analyzed the expression in different tissues from 4 different times (from newborn to weaning piglets) of Sutai pig (Duroc x Meishan) development. We discovered that the correlation between the TAP1 gene and E. coli F18 resistance could be used as a reference for the molecular mechanism of the TAP1 gene in E. coli F18 resistance.

\section{MATERIAL AND METHODS}

\section{Experimental materials and sample collection}

Sutai pig, which was generated by crossing a Duroc with a Taihu pig, is a high-quality and lean-meat breed. In this study, Sutai piglets were obtained from the Suzhou Sutai Pig 
Breeding Centre. We selected 8 individuals with similar birth weight, weaning weight, and figure from each of 4 groups: $8,18,30$, and 35 days (weaning). After sacrifice, the heart, liver, spleen, lung, kidney, stomach, thymus, lymph node, jejunum, duodenum, and muscle were collected in $1.5 \mathrm{~mL}$ Eppendorf nuclease-free tubes, stored immediately in liquid nitrogen, and then placed in a low-temperature freezer $\left(-80^{\circ} \mathrm{C}\right)$ until further study.

\section{Real-time PCR primer design}

Using the Primer Express 2.0 software, TAP1 primers were designed based on the sequence of NM001044581 (http://www.ncbi.nlm.nih.gov/) in GenBank and synthesized by Takara Biotechnology Dalian Co., Ltd. (China). GAPDH was used as an internal control to normalize all of the threshold cycle $(\mathrm{Ct})$ values of other tissue products. Primer sequences to amplify TAP1 and GAPDH are listed in Table 1.

\begin{tabular}{llc}
\multicolumn{2}{l}{ Table 1. Primers used for real-time polymerase chain reaction. } \\
\hline Gene & Sequence & Expected length (bp) \\
\hline TAP1 & Forward primer: 5'-CCACTGCTTTTCCTTCTGCCT-3' & 109 \\
GAPDH & Reverse primer: 5'-ACAGAACCTCAATGGCCACCT-3' & 187 \\
& Forward primer: 5'-ACATCATCCTGCTTCTACTGG-3' \\
& Reverse primer: 5'-CTCGGACGCCTGCTTCAC-3' & \\
\hline
\end{tabular}

\section{RNA extraction and fluorescence quantitative PCR}

Total RNA was extracted from various swine tissues $(50-100 \mathrm{mg})$ using Trizol reagent (TaKaRa Biotechnology Dalian Co., Ltd, China) according to manufacturer instructions. Precipitated RNA was resuspended in $20 \mu \mathrm{L}$ RNase-free $\mathrm{H}_{2} \mathrm{O}$ and then stored at $-80^{\circ} \mathrm{C}$. The RNA quality and quantity were assessed by agarose gel electrophoresis and ultraviolet (UV) spectrophotometry, respectively.

The $10-\mu \mathrm{L}$ reaction mixture for cDNA synthesis contained the following: $2 \mu \mathrm{L} 5 \mathrm{X}$ PrimerScript Buffer, $0.5 \mu \mathrm{L}$ PrimerScript RT Enzyme Mix I, $0.5 \mu \mathrm{L}$ oligo dT, $0.5 \mu \mathrm{L}$ random 6-mers, $500 \mathrm{ng}$ total RNA, and RNase-free $\mathrm{H}_{2} \mathrm{O}$ to make up the final volume of $10 \mu \mathrm{L}$. The reaction was carried out at $37^{\circ} \mathrm{C}$ for $15 \mathrm{~min}$ and then at $85^{\circ} \mathrm{C}$ for $5 \mathrm{~s}$.

Real-time PCR amplification was performed in a $20-\mu \mathrm{L}$ reaction mixture containing $1 \mu \mathrm{L}$ cDNA (100-500 ng), $0.4 \mu \mathrm{L} 10 \mu \mathrm{M}$ each forward and reverse primer, $0.4 \mu \mathrm{L} 50 \mathrm{X}$ ROX Reference Dye II, $10 \mu \mathrm{L} 2 \mathrm{X}$ SYBR Green Real-time PCR Master Mix, and $7.8 \mu \mathrm{L} \mathrm{ddH}_{2} \mathrm{O}$. The PCR conditions were $95^{\circ} \mathrm{C}$ for $15 \mathrm{~s}$, followed by 40 cycles of $95^{\circ} \mathrm{C}$ for $5 \mathrm{~s}$ and $62^{\circ} \mathrm{C}$ for $34 \mathrm{~s}$. The dissociation curve was analyzed after amplification. A peak melting temperature $(\mathrm{Tm})$ of 85 $\pm 0.8^{\circ} \mathrm{C}$ on the dissociation curve was used to determine the specificity of PCR amplification. The Tm value for each sample was the average of the real-time PCR data for triplicate samples.

\section{Data processing and analysis}

The $2^{-\Delta \Delta C t}$ method was used to process the real-time PCR results (Shaw et al., 2007). Statistical analyses were carried out using the SPSS 15.0 software (SPSS Inc, USA), and the Student $t$-test was carried out to determine the significance of differences in the mRNA expression between different groups. 


\section{RESULTS}

\section{Purity and integrity of total RNA}

Total RNA samples were assayed using $1 \%$ agarose gel electrophoresis. Three bands, representing $28 \mathrm{~S}, 18 \mathrm{~S}$, and $5 \mathrm{~S}$, were observed with no bands from DNA contamination or significant degradation. RNA purity was also examined on a UV spectrophotometer. The A260/ A280 ratios of the samples were 1.8-1.9.

\section{Fluorescence quantitative PCR amplification and melting curves}

The PCR amplification and dissociation curve for the TAP1 gene showed good repetition, and a single specific peak was observed with the real-time PCR products for the TAP1 gene with no primer dimers or nonspecific reaction products. The standard curves for the TAP 1 and GAPDH genes indicated that the amplification efficiencies of the target gene and the reference gene were almost the same, so that the $2^{-\Delta \Delta \mathrm{Ct}}$ method could be applied for quantitative calculation (Figure S1). Data were analyzed using SPSS 11.5 and are shown as means $\pm \mathrm{SD}$. The Student $t$-test was used to inspect the significance of expression differences in different populations.

\section{TAP1 gene expression in different tissues and growth stages}

Using the established SYBR green real-time quantitative PCR method described above, the expression levels of TAPl were examined in various tissues in this study. The expression level of TAP1 in the muscle of the resistance group was defined as 1.0. As the results show in Table 2, the tissue expression profiles of TAP1 in the 8, 18, and 30 days groups were similar. TAP1 has a low expression level in all 11 of the examined tissues, and the lung, lymph, duodenum, and jejunum had relatively high expression levels. However, the level increased significantly in the postweaning stage ( 35 days) $(\mathrm{P}<0.05)$, especially in intestinal tissues (duodenum and jejunum) and immune tissues (spleen, lymph, thymus, and lung). Additionally, the expression trend at 35 days was similar to that of the other ages.

\section{TAP1 Gene Ontology (GO) and pathway analysis}

According to the GO database classifications that were generated using the National Center for Biotechnology Information and the Kyoto Encyclopedia of Genes and Genomes database (http://www.genome.ad.jp/kegg/), the main function of the TAP1 gene was determined. The results indicated that TAP 1 was involved in 38 biological functions, including 3 categories: cellular component, molecular function, and biological process. In the biological process category, TAP1 was predicted to function in peptide receptor activation, binding to MHC I molecules, peptide transportation, and endogenous antigen presentation by MHC I. Moreover, as shown in Table 3, TAP1 was associated with 5 pathway processes, including $\mathrm{ABC}$ transporters, antigen processing and presentation, and primary immunodeficiency. 
Table 2. Differentiation of TAP1 mRNA expression in different growth stages.

\begin{tabular}{lcccc}
\hline Tissue & \multicolumn{3}{c}{ Growth stage (days) } \\
\cline { 2 - 5 } & \multicolumn{1}{c}{8} & 18 & 30 & 35 \\
\hline Heart & $1.79 \pm 0.90$ & $1.96 \pm 0.54$ & $6.31 \pm 1.26$ & $4.51 \pm 2.09$ \\
Liver & $8.04 \pm 5.90^{\mathrm{a}}$ & $2.80 \pm 1.38^{\mathrm{a}}$ & $5.62 \pm 0.17^{\mathrm{a}}$ & $24.83 \pm 5.72^{\mathrm{b}}$ \\
Spleen & $33.96 \pm 6.44^{\mathrm{a}}$ & $17.49 \pm 1.73^{\mathrm{A}}$ & $11.62 \pm 0.84^{\mathrm{A}}$ & $57.33 \pm 10.82^{\mathrm{B}}$ \\
Lung & $19.99 \pm 4.27^{\mathrm{A}}$ & $37.75 \pm 9.01^{\mathrm{A}}$ & $28.04 \pm 2.49^{\mathrm{A}}$ & $82.05 \pm 20.22^{\mathrm{B}}$ \\
Kidney & $6.25 \pm 1.07$ & $12.12 \pm 2.56$ & $13.74 \pm 4.10$ & $18.61 \pm 4.42$ \\
Stomach & $16.70 \pm 5.53$ & $29.11 \pm 6.87$ & $23.80 \pm 5.66$ & $51.19 \pm 14.83$ \\
Muscle & $1.00 \pm 0.00$ & $1.00 \pm 0.00$ & $1.00 \pm 0.00$ & $1.00 \pm 0.00$ \\
Thymus & $20.26 \pm 5.95^{\mathrm{a}}$ & $15.60 \pm 6.85^{\mathrm{a}}$ & $12.80 \pm 1.14^{\mathrm{a}}$ & $74.35 \pm 20.49^{\mathrm{b}}$ \\
Lymph & $18.78 \pm 3.12^{\mathrm{A}}$ & $23.23 \pm 8.05^{\mathrm{A}}$ & $36.81 \pm 0.16^{\mathrm{a}}$ & $108.48 \pm 21.51^{\mathrm{B}}$ \\
Duodenum & $20.90 \pm 6.66^{\mathrm{a}}$ & $28.76 \pm 2.80^{\mathrm{a}}$ & $40.73 \pm 5.48^{\mathrm{a}}$ & $80.07 \pm 6.19^{\mathrm{b}}$ \\
Jejunum & $20.02 \pm 4.02^{\mathrm{A}}$ & $22.56 \pm 3.13^{\mathrm{A}}$ & $31.58 \pm 9.74^{\mathrm{A}}$ & $138.18 \pm 19.05^{\mathrm{B}}$ \\
\hline
\end{tabular}

Values in same columns with small letters indicate $\mathrm{P}<0.05$, and those with capital letters indicate $\mathrm{P}<0.01$.

\begin{tabular}{lll}
\multicolumn{2}{c}{ Table 3. Analysis results of TAP1 gene pathways. } \\
\hline Number & KEGG & Name \\
\hline 1 & $\operatorname{ssc} 02010$ & ABC transporters \\
2 & $\operatorname{ssc} 04145$ & Phagosome \\
3 & $\operatorname{ssc} 04612$ & Antigen processing and presentation \\
4 & $\operatorname{ssc} 05168$ & Herpes simplex infection \\
5 & $\operatorname{ssc} 05340$ & Primary immunodeficiency \\
\hline
\end{tabular}

KEGG $=$ Kyoto Encyclopedia of Genes and Genomes.

\section{DISCUSSION}

TAP1 plays a critical role in mediating cell endogenous antigen and binding to MHC I for recognition by cytotoxic T-lymphocytes. At the same time, most of reports considered that the TAPI gene was associated with viral infection and tumors. Virus inhibits peptide presentation and blocks the $\mathrm{T}$ cell recognition of the infected cells, and it avoids host immune response through resistance mechanisms (Zeidler et al., 1997; Ambagala et al., 2000, 2003; Bauer and Tampé, 2002). For E. coli F18, the primary causative agent of diarrhea and edema is the enterotoxin, including heat-labile enterotoxin, heat-stable enterotoxin, and shiga toxin. These enterotoxins can act as the antigens, and TAP can be involved in transporting the enterotoxin peptides to the cell surface to induce the specific recognition of $\mathrm{CD} 8^{+} \mathrm{T}$ cells. Lipopolysaccharide (LPS), the dominant components of the gram-negative bacterium E. coli F18 cell wall, is one of the primary infectious agents. Sun et al. (2012) found that the TAPl expression level increased in the pig kidney cell line (PK-15) when it was infected with LPS. Therefore, TAP1 is closely associated with $E$. coli F18 infection in piglets.

The TAP1 studies in this manuscript showed that postweaning and unweaned piglet tissues had similar expression-profile trends. TAP1 has a relatively high expression level in immune tissues (spleen, lymph, thymus, and lung) and intestinal tissues (duodenum and jejunum). In the MHC I metabolic pathway, TAP1 participated in several stages. First, the proteosome degraded the antigenic peptides in the cytosol into small peptides. Next, with the assistance of HSP70 and HSP50, TAP carried the small peptides from the cytosol to the endoplasmic reticulum. Then, assisted by Tapasin, mature BRp57, CALR, and B2m carried the antigenic 
peptides into the golgiosome. Finally, after processing, these complexes were transported to the cell membrane to induce the specific recognition and processing by $\mathrm{CD} 8^{+} \mathrm{T}$ cells and NK cells (Ambagala et al., 2000). The high expression level of TAP in immune tissue is due to its disease resistance. The lungs contact the environment directly, so the lung is important in the immune system. With TAP mediation, the MHC I antigenic presentation pathway can also mediate the recognition and resistance of bacteria and virus efficiently; therefore, TAPl is highly expressed in the lung. Sun et al. (2012) detected the tissue expression profile of Chinese crossing pig breeds (30-40 days) in Guangdong Province. The high expression level of TAP1 in lymph and lung was similar to observations in our research. However, one difference was that TAPl had a low expression level in intestines. This difference may result from complications associated with the sample genetic background and unequal sample size. The high expression level of $T A P 1$ in lung may result because the piglet lung is vulnerable to infection, and previous reports indicated that many disease-resistance genes were expressed highly in lungs, such as TLR4 (Bao et al., 2011). Therefore, it is clear that the high expression level of the TAP1 gene in immune tissues corresponds with its immune function in antigen presentation.

In this study, the high expression level of TAPI in the intestine implied that TAPI had a potential relationship with piglet intestinal disease. The duodenum and jejunum are vulnerable for bacteria and viruses, so the importance of the TAP protein in resisting bacteria and recognizing virus induces a high expression level in the duodenum and jejunum. Studies showed that TAP was related to anti-gram-negative bacterium immunity. Schultz et al. (2003) found that patients without TAP are more likely to become infected by gram-negative bacteria because bactericidal/permeability-increasing protein activity was inhibited. In addition, patients without TAP are more likely to be infected by gram-negative bacteria than by a virus (de la Salle et al., 1994, 1999). E. coli F18 mainly infects the duodenum and jejunum. In the piglet's small intestine, E. coli $\mathrm{F} 18$ adhered to the surface of epithelial cells by its fimbriae, was recognized by F18 recognition protein, and activated TAP by specific cell signaling. Then, the activated TAP started the antigenic presentation and processing, adaptive immunity activation, and NF- $\kappa$ B activation. In the end, IL-6, TNF- $\alpha$, IFN- $\gamma$, and the other cytokines are synthesized and released to extracellular regions to stimulate inflammatory reactions, which include granulocyte and macrophage chemotactic aggregation, telangiectasia, and lymphocytic infiltration. Thus, TAP can resist $E$. coli F18 infection and has the characteristic of high resistance.

The tissues expression profiles showed that TAP1 had a low expression level in all of the examined tissues in unweaned and postweaning stages, but in intestinal tissues (duodenum and jejunum) and immune tissues (spleen, lymph, thymus, and lung) it was significantly increased $(\mathrm{P}<0.05)$. The tissue expression levels were not significantly different among the 3 unweaned stages of 8,18 , and 30 days $(\mathrm{P}>0.05)$. Nevertheless, the postweaning expression level in 7 tissues (spleen, lung, lymph, duodenum, jejunum, liver, and thymus) was significantly higher than the expression level in the unweaned stages $(\mathrm{P}<0.05)$. Bertschinger et al. (1990) reported that newborn piglets were more susceptible to infection by $E$. coli $\mathrm{F} 4$, while postweaning piglets were more susceptible to infection by $E$. coli F18. According to the results above and the epidemiological characteristics of diarrhea and edema in piglets, this study indicated that the TAP1 gene may play an important role in resisting infection by E. coli F18 in weaning piglets.

\section{ACKNOWLEDGMENTS}

Research supported by the National Natural Science Funds (\#31172183, \#31372285), 
the Prospective Joint Research Project of Jiangsu Province (\#BY2012157), the Science and Technology Supporting Project of Jiangsu Province (\#BE2012330, \#BE2013345), and the Priority Academic Program Development of Jiangsu Higher Education Institutions (PAPD).

\section{Supplementary material}

\section{REFERENCES}

Ambagala AP, Hinkley S and Srikumaran S (2000). An early pseudorabies virus protein down regulates porcine MHC class I expression by inhibition of transporter associated with antigen processing (TAP). J. Immunol. 164: 93-99.

Ambagala AP, Gopinath RS and Srikumaran S (2003). Inhibition of TAP by pseudorabies virus is independent of its vhs activity. Virus Res. 96: 37-48.

Bao WB, Wu SL, Musa HH, Zhu GQ, et al. (2008). Genetic variation at the alpha-1-fucosyltransferase (FUT1) gene in Asian wild boar and Chinese and Western commercial pig breeds. J. Anim. Breed. Genet. 125: 427-430.

Bao WB, Pan ZY, Zhu J, Ye L, et al. (2011). Differentiation of porcine TLR4 gene mRNA expression between resistant and sensitive resource populations to ETEC F18. Acta Vet. Zootech. Sin. 42: 278-283.

Bao WB, Ye L, Pan ZY, Zhu J, et al. (2012). Microarray analysis of differential gene expression in sensitive and resistant pig to Escherichia coli F18. Anim. Genet. 43: 525-534.

Bauer D and Tampé R (2002). Herpes viral proteins blocking the transporter associated with antigen processing TAP-from genes to function and structure. Curr. Top. Microbiol. Immunol. 269: 87-99.

Bertin AM and Duchet-Suchaux MF (1991). Relationship between virulence and adherence of various enterotoxigenic Escherichia coli strains to isolated intestinal epithelial cells from Chinese Meishan and European large white pigs. Am. J. Vet. Res. 52: 45-49.

Bertschinger HU, Bachmann M, Mettler C, Pospischil A, et al. (1990). Adhesive fimbriae produced in vivo by Escherichia coli $\mathrm{O} 139: \mathrm{K} 12(\mathrm{~B}): \mathrm{H} 1$ associated with enterotoxaemia in pigs. Vet. Microbiol. 25: 267-281.

Chen HY and Wu ZF (2009). Prospective of $B F, D R B, D Q B$, TAPI and $I F N-\gamma$ genes used as porcine marker assisted disease resistance and breeding. Biotechnol. Bull. 1: 103-106.

Cresswell P, Bangia N, Dick T and Diedrich G (1999). The nature of the MHC class I peptide loading complex. Immunol. Rev. 172: 21-28.

de la Salle H, Hanau D, Fricker D, Urlacher A, et al. (1994). Homozygous human TAP peptide transporter mutation in HLA class I deficiency. Science 265: 237-241.

de la Salle H, Zimmer J, Fricker D, Angenieux C, et al. (1999). HLA class I deficiencies due to mutations in subunit 1 of the peptide transporter TAP1. J. Clin. Invest. 103: R9-R13.

Pamer E and Cresswell P (1998). Mechanisms of MHC class I-restricted antigen processing. Annu. Rev. Immunol. 16: 323-358.

Schultz H, Schinke S, Weiss J, Cerundolo V, et al. (2003). BPI-ANCA in transporter associated with antigen presentation (TAP) deficiency: possible role in susceptibility to Gram-negative bacterial infections. Clin. Exp. Immunol. 133: 252-259.

Shaw AE, Reid SM, Ebert K, Hutchings GH, et al. (2007). Implementation of a one-step real-time RT-PCR protocol for diagnosis of foot-and-mouth disease. J. Virol. Methods 143: 81-85.

Sun N, Liu D, Chen H, Liu X, et al. (2012). Localization, expression change in PRRSV infection and association analysis of the porcine TAP1 gene. Int. J. Biol. Sci. 8: 49-58.

Vögeli P, Meijerink E, Fries R, Neuenschwander S, et al. (1997). A molecular test for the detection of E. coli F18 receptors: a breakthrough in the struggle against edema disease and post-weaning diarrhea in swine. Schweiz. Arch Tierheilkd. 139: 479-484.

Zeidler R, Eissner G, Meissner P, Uebel S, et al. (1997). Downregulation of TAP1 in B lymphocytes by cellular and Epstein-Barr virus-encoded interleukin-10. Blood 90: 2390-2397. 